\title{
Racecadotril (Acetorphan) for Diarrhea in Adults Infected with HIV/AIDS: A Meta-Analysis and Systematic Review
}

\author{
Ronna Cheska V. De Leon, ${ }^{1}$ Harold Henrison C. Chiu, ${ }^{1}$ Kim Paul B. De Castro, ${ }^{1}$ \\ Jhoanna Rose H. Velasquez ${ }^{1}$ and Antonio Miguel L. Dans ${ }^{2}$ \\ ${ }^{1}$ Department of Medicine, Philippine General Hospital, University of the Philippines Manila \\ ${ }^{2}$ Division of Adult Medicine, Department of Medicine, College of Medicine and Philippine General Hospital, University of the Philippines Manila
}

\begin{abstract}
Background. Diarrhea is a common and disabling symptom seen in patients with Human Immunodeficiency Virus (HIV) infection and the Acquired Immune Deficiency Syndrome (AIDS). The diarrhea is chronic and results in malabsorption contributing to cachexia. Symptomatic treatment can improve the quality of life and nutritional status of these patients.

The endogenous group of opiates known as enkephalins function as anti-secretory agents without affecting intestinal transit. Racecadotril (acetorphan) is an orally active enkephalinase inhibitor. Available studies have focused on the use of racecadotril in healthy adults and children with acute infectious diarrhea.
\end{abstract}

Objectives. To assess the efficacy of racecadotril (acetorphan) in reducing the duration and frequency of bowel movement in adult HIV patients with chronic diarrhea.

Methods. Electronic databases were searched for randomized controlled trials which used racecadotril for chronic diarrhea in HIV patients. Three independent reviewers assessed the quality of the two studies based on the Cochrane Infectious Disease Group prior to inclusion in study. Data extracted were analyzed using Revman Version 5. Test for heterogeneity was performed using the chi square test.

Results. Results showed the standardized mean difference for the two trials comparing racecadotril to placebo and octreotide in reducing bowel movements from baseline was $-1.00(95 \% \mathrm{Cl}-1.16$ to $-0.84, \mathrm{Z}=12.08, \mathrm{p}<0.00001)$, showing a beneficial effect. Response rate for the two trials comparing racecadotril to placebo or octreotide in reducing bowel movements from baseline was $-0.13(95 \% \mathrm{Cl}-0.26$ to $0.01, \mathrm{Z}=1.84, \mathrm{p}<0.07)$, showing a trend towards benefit in terms of response rates. Heterogeneity was statistically insignificant $\left(p=1, I^{2}=0 \%\right)$.

Conclusions. There is evidence pointing to a benefit in using racecadotril in HIV and AIDS-associated, non-infectious diarrhea by decreasing the frequency of loose stools. An individualized approach is still recommended in its use for HIV patients with chronic diarrhea.

Key Words: Racecadotril, enkephalinase inhibitors, chronic diarrhea, AIDS

\section{INTRODUCTION}

Paper won $1^{\text {st }}$ Place at the $48^{\text {th }}$ Philippine College of Physicians Annual Convention Meta-Analysis Category, April 29 - May 2, 2018, SMX Convention Center, Manila, Philippines.

Corresponding author: Harold Henrison C. Chiu, MD Department of Medicine

Philippine General Hospital

University of the Philippines Manila

Taft Avenue, Manila 1000, Philippines

Email: hcchiu@up.edu.ph
Diarrhea is a common symptom found in patients diagnosed with Human Immunodeficiency Virus (HIV). The common causes of diarrhea in this population are usually infectious in origin involving viruses, fungi, bacteria, and helminths. In developed countries, Cryptosporidium, microsporidia, and Isospora belli are the most common opportunistic protozoa that infect the gastrointestinal tract and cause diarrhea in HIV-infected patients. ${ }^{1}$ Cryptosporidial infections can present from a self-limited or 
intermittent diarrheal illness to a severe, life-threatening diarrhea in severely immunodeficient individuals. The incidence of cryptosporidiosis is $\sim 1 \%$ per year in untreated patients with CD4+ T cell counts of $<300 / \mathrm{uL}$. Therapy is mainly supportive and there have been marked improvements since the advent of protease inhibitors and nucleoside reverse transcriptase inhibitors. In contrast, in developing countries in Southeast Asia, the most common causes of infectious diarrhea in HIV patients include gastrointestinal tuberculosis and Salmonella for which appropriate antimicrobial therapy remain as first line treatment. ${ }^{2}$

Etiologies of non-infectious diarrhea in this population are multifactorial, including adverse effects of antiretroviral therapy (ARTs), HIV enteropathy, and less commonly, HIV-related malignancies..$^{3-5} \mathrm{HIV}$ enteropathy is postulated to be a direct result of HIV infection of the gastrointestinal tract. The most common mechanisms identified include the alteration of the intestinal barrier function; increasing calcium-dependent chloride ion secretion accompanied by sodium and water; and infection of the enterocytes by the virus causing villous atrophy, villous blunting, and crypt hyperplasia causing enteral leaks. Since the advent of the use of ARTs, the life expectancy and quality of life of patients with HIV have improved significantly.,4 One of the common untoward effects of ARTs is non-infectious diarrhea, defined as greater than four loose, watery stools in a day. The disabling symptoms such as diarrhea also contribute to the decreased adherence of patients to ARTs. ${ }^{3}$

Management of HIV/AIDS-associated non-infectious diarrhea include nonpharmacologic measures such as dietary modifications (high soluble fiber, low insoluble fiber, lactosefree and caffeine-free diets), bulking agents (oat bran and psyllium), and probiotics. Anti-inflammatory agents such as bovine serum-derived immunoglobulin and curcumin are also being identified as potential treatment strategies in HIV-associated diarrhea. ${ }^{3}$ The use of acupuncture and moxibustion for the treatment of gastrointestinal symptoms in HIV are also available, though results are not yet that promising. ${ }^{3}$ Pharmacologic interventions that have been studied for HIV/AIDS-associated non-infectious diarrhea include adsorbents (attapulgite and bismuth subsalicylate) which help improve stool consistency. Antimotility agents such as opiate derivatives (loperamide) and atropine run the risk of enhancing microbial proliferation and delayed fecal elimination of pathogens. ${ }^{4}$

New anti-diarrheal agents with different modes of action are needed. Ideally, these agents should inhibit excessive fluid secretion in the intestinal lumen as well as stimulate mucosal absorption. ${ }^{4}$ Octreotide, a long-acting somatostatin analogue, has shown promising anti-motility characteristics and efficacy in the treatment of HIV/AIDSassociated diarrhea. ${ }^{3,4}$ However, octreotide requires parenteral administration, inhibits biliary and pancreatic secretion further contributing to the HIV/AIDS-related cachexia due to fat and protein malabsorption. ${ }^{4}$ The endogenous group of opiates known as enkephalins were discovered in $1975 .^{4-19}$ They act as neurotransmitters along the gastrointestinal tract where they function as anti-secretory agents without affecting intestinal transit. Racecadotril (acetorphan) is an orally active enkephalinase inhibitor, exhibiting intestinal anti-secretory activity both in humans ${ }^{14,15}$ and animals ${ }^{16}$ without contributing to intestinal transit time. Although several studies about this drug have been reported in the literature, most if not all studies, have focused on healthy adults ${ }^{4-11,17}$ with acute infectious diarrhea and the pediatric population. ${ }^{13}$ To date, only two randomized trials $s^{4,5}$ have been reported in adult patients with HIV/AIDS-associated non-infectious diarrhea; both trials were conducted during the pre-antiretroviral era. Given the rising cases of HIV/AIDS worldwide, with antiretroviral and antimicrobial agents becoming more available and accessible, the incidence of infectious causes of diarrhea has declined and there is a shift towards more cases of HIV/ AIDS-associated diarrhea encountered in daily practice. ${ }^{3}$ This study aimed to give an updated summary of evidence, as well as progress, in terms of the utility of racecadotril in the treatment of HIV/AIDs-associated non-infectious diarrhea.

\section{OBJECTIVES}

\section{General Objective}

To assess the efficacy of racecadotril compared to any intervention for the treatment of HIV/AIDS-associated non-infectious diarrhea measured through diarrheal duration and frequency

\section{Specific Objectives}

1. To assess the response rate to racecadotril compared to any intervention in reducing diarrhea duration and frequency

2. To evaluate the effect of racecadotril on fecal nitrogen and lipid output and adverse events

\section{METHODS}

\section{Criteria for considering studies for this review}

\section{Types of studies}

The trials were randomized trials in an in-patient or outpatient basis

\section{Types of Participants}

Participants of this study included HIV patients above 18 years of age with chronic non-infectious diarrhea defined as the passage of five or more episodes of unformed stools per day for more than one month.

\section{Types of Intervention}

Patients in the experimental group received racecadotril at a dose of $100 \mathrm{mg}$ per day up to a maximum dose of 300 mg per day while patients in the control group received either 
octreotide 50 ug subcutaneous injection per day up to a maximum dose of $150 \mathrm{ug}$ per day or placebo.

\section{Types of outcome measures}

Primary outcomes measured were the stool frequency and stool weight. Secondary outcome measures included: (1) fecal nitrogen output, (2) fecal lipid output, and (3) adverse effects.

\section{Search methods for identification of studies}

\section{Electronic searches}

A highly sensitive search strategy was used for identifying randomized controlled trials. Both electronic and manual means of retrieving relevant studies were performed. Electronic searches (search strategy not limited by language and publication status) were completed using PUBMED, MEDLINE (1966 to 24 April 2017; National Library of Medicine, Bethesda, USA), EMBASE (1974 to 24 April 2017; Elsevier Science, New York, USA), Cochrane Central Register of Controlled Trials, Google Scholar, and Cochrane Inflammatory Bowel Disease and Functional Bowel Disorder Group Specialized Trials Register. The reference lists of all identified papers were searched for further information.

The search strategy combined the search terms "randomized controlled trials", "racecadotril", "AIDS", and "diarrhea". The following search terms were used in the PUBMED search strategy: ("racecadotril"[Supplementary Concept] OR "racecadotril"[All Fields] OR "acetorphan"[All Fields]) AND ("acquired immunodeficiency syndrome"[MeSH Terms] OR ("acquired"[All Fields] AND "immunodeficiency"[All Fields] AND "syndrome"[All Fields]) OR "acquired immunodeficiency syndrome"[All Fields] OR "aids"[All Fields]). A diagram illustrating the summary of our search strategy is shown below (Figure 1).

\section{Other resources}

For articles that were either unpublished or with fulltext not available in the internet, the authors were contacted via their respective emails and through www.researchgate. net. The articles were received via email from the authors who responded.

\section{Selection criteria}

Randomized controlled trials were included in this systematic review. Participants were aged 18 years old and above, of either sex with a confirmed diagnosis of HIV with associated chronic non-infectious diarrhea (defined as the passage of five or more episodes of unformed stools per day for more than one month). Studies that included pediatric patients, or patients suffering from infectious bloody diarrhea were excluded from the study. Those with acute ulcerative colitis or pseudomembranous colitis in association with broad-spectrum antibiotics were excluded as well.

\section{Data collection and analysis}

\section{Data extraction}

Three independent reviewers assessed the methodological quality of the studies according to the criteria used by the Cochrane Infectious Disease Group. Each of the co-authors independently evaluated the suitability of each study for inclusion in the meta-analysis; the results of these individual assessments were then compared. In cases in which the original opinions varied, these differences were resolved through consensus by using the pre-established inclusion criteria. Studies were assessed as high-quality if they fulfilled the following criteria: (1) treatment allocation was randomized with adequate concealment; (2) the treatment and control groups were balanced in terms of known determinants of outcome; (3) outcome assessment

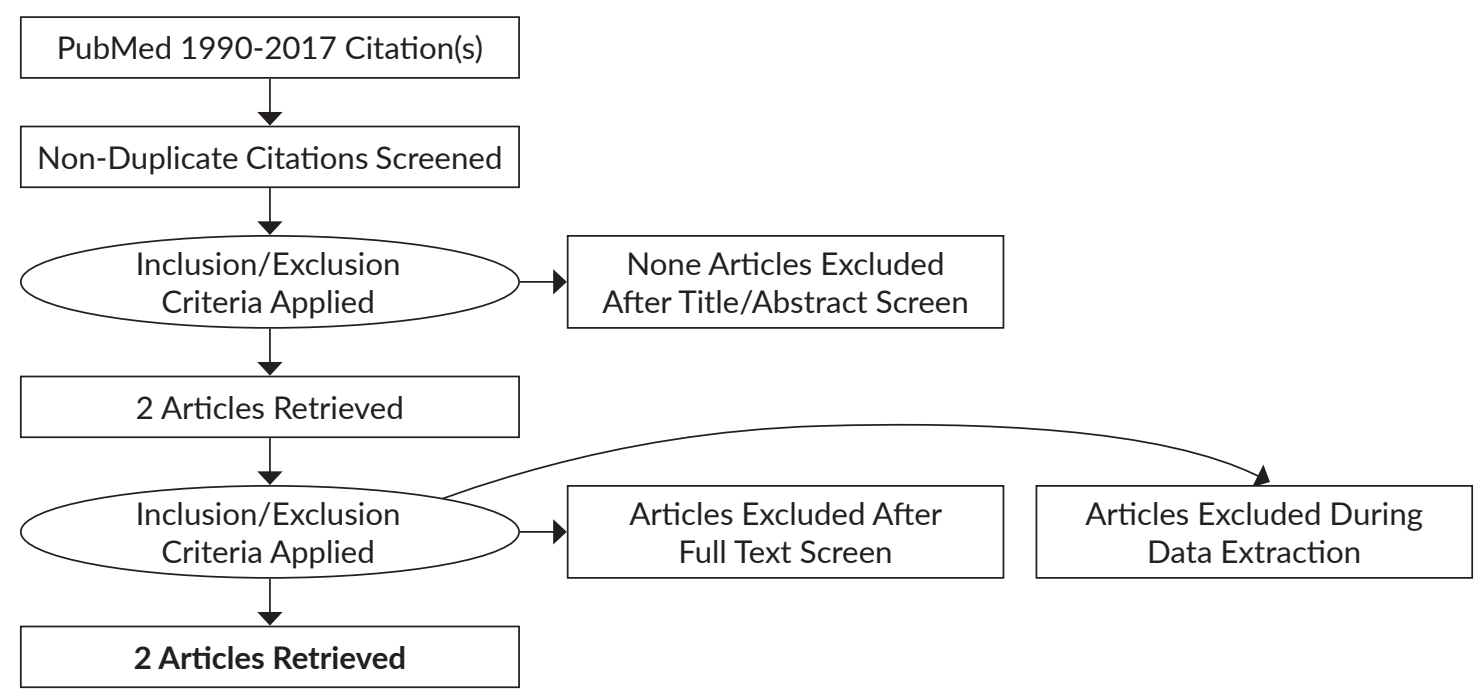

Figure 1. PRISMA flow chart showing the inclusion and exclusion of articles. 
Table 1. Description of studies

\begin{tabular}{|c|c|c|c|c|c|c|}
\hline \# Author, Year & Study Design & Sample size (n) & Population & Intervention & Control & Outcome Available \\
\hline $\begin{array}{l}1 \text { Baumer, } \\
\text { et al., } 1995\end{array}$ & $\begin{array}{l}\text { Randomized } \\
\text { double blind } \\
\text { controlled trial }\end{array}$ & 174 & $\begin{array}{l}\text { HIV-infected patients } \\
\text { complaining of chronic diarrhea } \\
\text { defined as }>5 \text { stools/day for }>1 \\
\text { month }\end{array}$ & $\begin{array}{l}\text { Acetorphan } 100 \\
-200 \mathrm{mg} \text { three } \\
\text { times a day }\end{array}$ & $\begin{array}{l}\text { Placebo tablets } \\
100-200 \mathrm{mg} \\
\text { three times a day }\end{array}$ & $\begin{array}{l}\text { Reduction in } \\
\text { frequency of stools }\end{array}$ \\
\hline $\begin{array}{l}2 \text { Beaugerie } \\
\text { et al., } 1996\end{array}$ & $\begin{array}{l}\text { Open } \\
\text { randomized } \\
\text { crossover study }\end{array}$ & 13 & $\begin{array}{l}\text { Adults with AIDS-associated } \\
\text { diarrhea ( }>5 \text { unformed stools/day } \\
\text { for }>1 \text { month with an average } \\
\text { stool weight of } 400 \mathrm{~g} / 24 \mathrm{~h} \text { ) }\end{array}$ & $\begin{array}{l}\text { Acetorphan } \\
100 \text { mg capsule } \\
\text { up to three } \\
\text { times daily }\end{array}$ & $\begin{array}{l}\text { Octreotide } 50 \text { ug } \\
\text { subcutaneous } \\
\text { injection up to } \\
\text { three times daily }\end{array}$ & $\begin{array}{l}\text { Reduction in stool } \\
\text { frequency, weight, } \\
\text { and lipid content }\end{array}$ \\
\hline
\end{tabular}

was done in a double-blind manner; (4) outcome detection methods used were similar for both groups; (5) treatment and control groups were treated equally in terms of other therapeutic and co-interventions received, frequency of follow-up, and general quality of care; (6) an intention-totreat analysis was conducted; and (7) drop-out rates between groups were comparable. On the other hand, studies were considered fair-quality if any subtle biases were present, such as: (1) unclear allocation concealment; (2) absence of blinding; or (3) no intent-to-treat analysis. And lastly, studies were considered low-quality if any of the frank biases was seen: (1) significant differences between the treatment and control groups in terms of known predictors of outcome; (2) obvious differences in the general quality of care received by subjects in both groups; (3) marked difference in dropout rates; or (4) outcome detection methods were different for both groups.

\section{Data analysis}

All the outcome measures were combined and analyzed using a fixed-effect model in Review Manager (RevMan) Version 5. The outcomes were continuous, based on the definition by the Cochrane Handbook of Systematic Reviews. It was classified as dichotomous if the outcome was one of only two possible categorical responses. For dichotomous data, the risk ratio or the probability that an event will occur was determined for each comparison. Continuous data was defined as those that can take any value in a specified range. The standardized mean difference (SMD) was used to combine results from studies using different ways of measuring the same concept. The stool frequency, stool weight, duration of diarrhea, fecal nitrogen output and fecal lipid output were all considered continuous data in this review.

\section{Test for Heterogeneity}

Heterogeneity was quantified using the chi square test for heterogeneity with $p<0.10$ as the cut-off for significant heterogeneity. Heterogeneity can be interpreted as a percentage of total variation between studies that is attributable to heterogeneity rather than to chance. $\mathrm{I}^{2}$ test was used to assess the degree of heterogeneity, i.e. $\mathrm{I}^{2}>50 \%$ suggests significant degree of heterogeneity or a value of $0 \%$ indicates no observed heterogeneity.

\section{RESULTS}

\section{Description of studies}

After searching PUBMED and the Cochrane Central Register of Controlled Trials (CENTRAL), a total of 2 studies were identified to be potentially eligible for inclusion in the meta-analysis (Table 1). After thorough scrutiny, no articles were excluded (Figure 1). Two studies were left for more detailed review; reference lists of articles were reviewed and no additional trials were identified.

Two randomized controlled trials involving 187 participants (racecadotril $=84$; control $=87$ ) met our inclusion criteria. ${ }^{1-2}$ Both studies were included in this analysis. Both investigated the effect of racecadotril (acetorphan) in HIV and AIDS-associated diarrhea. These studies, however, slightly differed in terms of control. One study compared racecadotril with placebo (Baumer 1995) while the other study compared racecadotril with octreotide (Beaugerie 1996). Both studies measured the reduction in stool frequency which served as the main outcome. One study further explored stool weight, stool nitrogen and lipid content, and adverse events (Beaugerie 1996).

Both trials were conducted in France. Participants of the studies were adults with HIV, aged 18 years old and above. One study was conducted on in-patient with HIVassociated diarrhea (Beaugerie 1996), while the other study was conducted on an outpatient setting (Baumer 1995).

\section{Quality assessment of included studies}

Based on the criteria set by Cochrane Infectious Disease Group, the quality of the retrieved studies was assessed independently by the three authors. The trials included in this study were randomized at level of treatment. However, not all studies described their method of allocation generation concealment; the study by Baumer (1995) showed a high attrition and selective reporting bias. On the other hand, the study of Beaugerie (1996) noted high selection, performance and detection bias (Figure 2).

\section{Effects on Intervention on Outcomes of Interest}

\section{Stool frequency}

Both studies assessed the effects of racecadotril on the number of bowel movements in 7 days compared to 

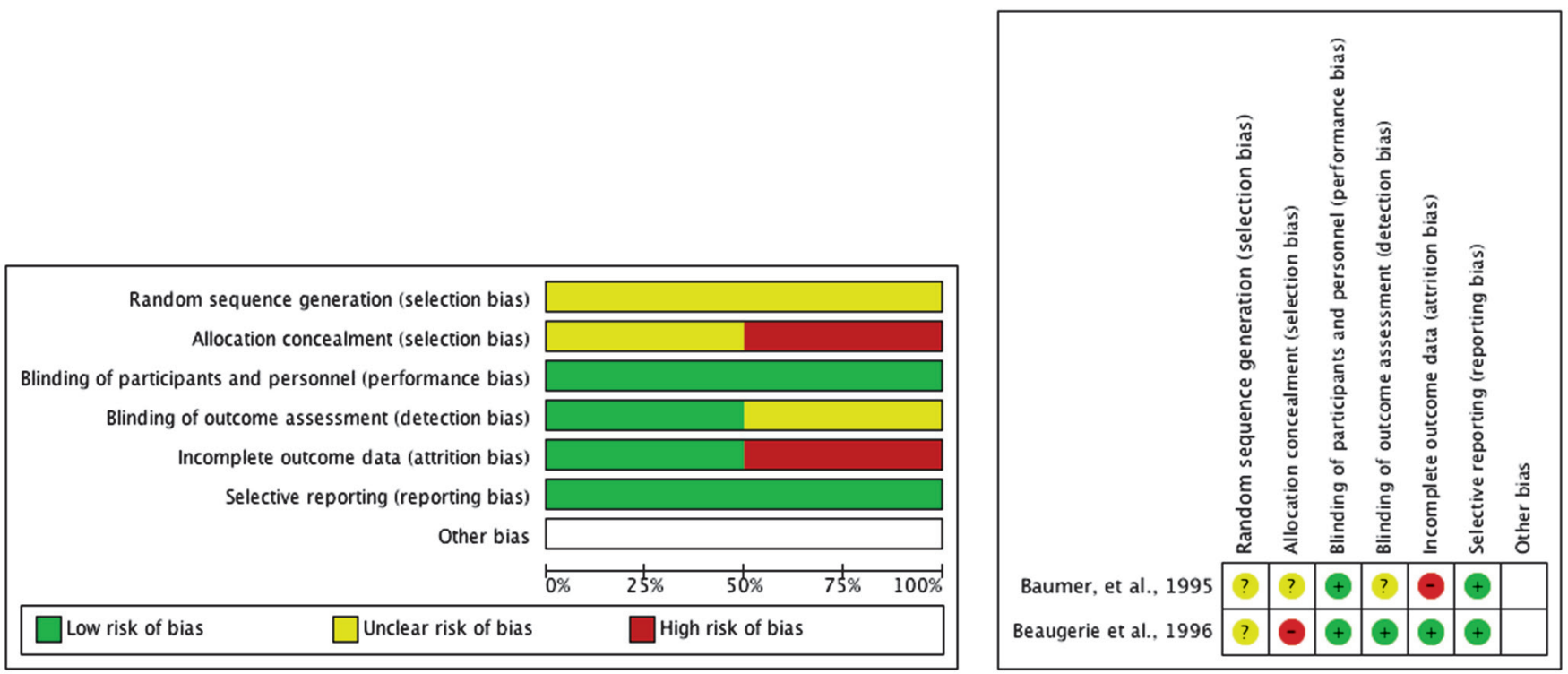

Figure 2. Quality assessment of included studies.

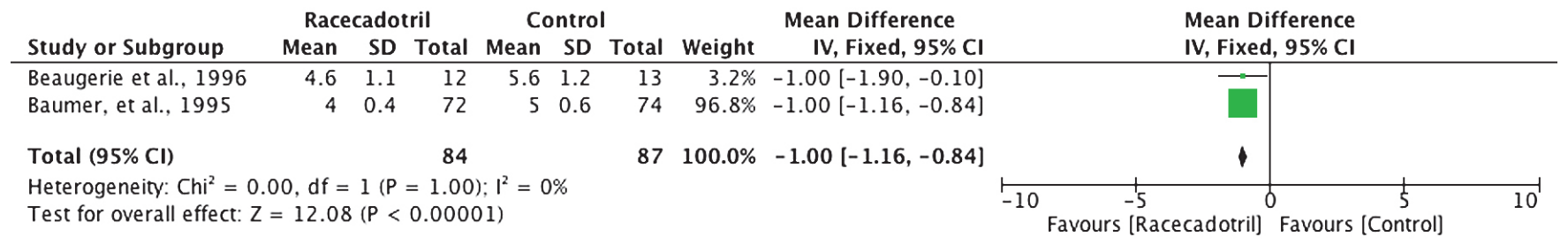

Figure 3. Stool frequency measured as episodes per day after 7 days of treatment.

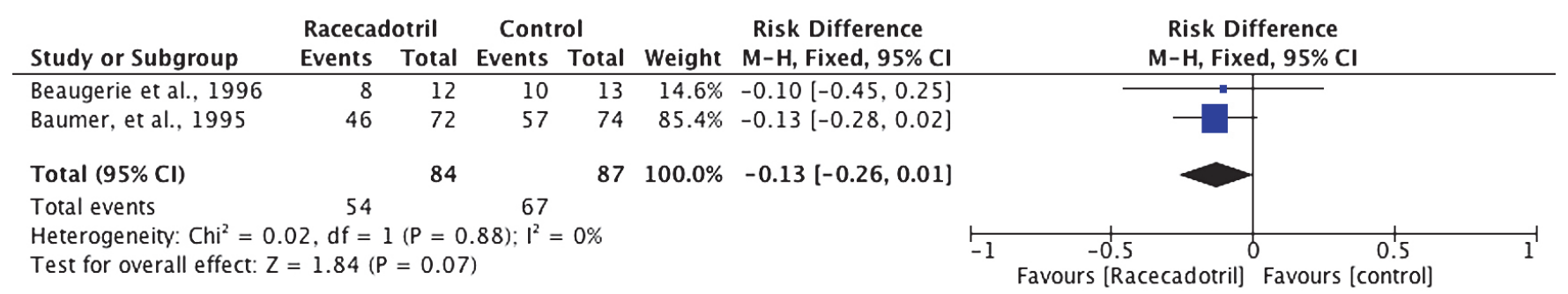

Figure 4. Response to treatment; full responders defined as $33 \%$ decrease in stool frequency after the intervention.

placebo $^{2}$ or treatment control ${ }^{1}$. The standardized mean difference (SMD) for the two trials comparing racecadotril to another intervention in reducing bowel movements from baseline to that after treatment was -1.00 (95\% CI -1.16 to $-0.84, Z=12 / 08, p<0.00001)$. Heterogeneity was statistically insignificant $\left(\mathrm{p}=1, \mathrm{I}^{2}=0 \%\right)$ (Figure 3$)$.

\section{Response rates}

Both studies measured the number of full responders (defined as a $33 \%$ reduction in stool frequency after the intervention). Response rate was calculated. The response rate for the two trials comparing racecadotril to placebo or octreotide in reducing bowel movements from baseline to that after treatment was $-0.13(95 \%$ CI -0.26 to
$0.01, Z=1.84, p<0.07)$. Heterogeneity was statistically insignificant $\left(\mathrm{p}=1, \mathrm{I}^{2}=0 \%\right)$ (Figure 4).

\section{Stool weight}

Only the study by Baumer et al. measured the stool weight in response to treatment with racecadotril versus octreotide. It was shown that the stool weight was not significantly modified by either of the two treatments. ${ }^{5}$

\section{Stool lipid and nitrogen content}

In the study by Baumer et al., fecal lipid output was decreased by $39 \%$ in the racecadotril group and increased by $78 \%$ in the octreotide group. However, this was not statistically significant. Fecal nitrogen output was not markedly modified. ${ }^{5}$ 


\section{Adverse events}

Only one study (Beaugerie 1996) provided information about adverse events. A significant difference in the frequency of adverse events between the experimental group and control group was not demonstrated. Reported adverse events for the trial were nausea, anorexia, anal burning, spontaneous abdominal pain, pain on abdominal palpation, and abdominal distension. ${ }^{4}$

\section{DISCUSSION}

Diarrhea is a common symptom experienced by patients with HIV. It greatly affects their quality of life. A lot of studies looked into different interventions which may help improve symptoms. This meta-analysis included two studies which assessed the efficacy of racecadotril in the treatment of HIV-associated, non-infectious diarrhea. In the analysis of the data available, racecadotril significantly decreased the frequency of bowel movement compared to placebo or treatment control, in this case octreotide. The standardized mean difference for the two trials comparing racecadotril to another intervention in reducing bowel movements from baseline to that after treatment was -1.00 (95\% CI -1.16 to $-0.84, Z=12 / 08, p<0.00001)$. Heterogeneity within the studies were also analyzed, showing statistic insignificance $\left(\mathrm{p}=1, \mathrm{I}^{2}=0 \%\right)$.

It is important to take into consideration that racecadotril was compared to two different interventions in the studies included in the meta-analysis. Baumer, et al. compared the effects of racecadotril to placebo while Beaugerie, et al. evaluated its effects compared to octreotide, a synthetic analogue of somatostatin. This substance has shown to have an effect in the treatment of patients with severe, refractory diarrhea in HIV patients ${ }^{18}$, in part by altering the motility of the small intestine. ${ }^{19} \mathrm{~A}$ multicenter, prospective clinical trial conducted by Cello, et al. in 1991 compared the effects of octreotide to placebo. They noted a significant decrease in both stool frequency and volume in the treatment group for HIV patients with infectious and non-infectious diarrhea. On the other hand, a double-blind, placebo-controlled study by Simon, et al. in 1995 showed a non-significant decrease in the stool weight in those treated with octreotide, compared to placebo, in HIV patients with diarrhea. ${ }^{19}$ Bearing this in mind, we should interpret the generalizability of the results with caution.

Both studies also took into consideration the number of full responders to racecadotril, defined as a $33 \%$ reduction in stool frequency after the intervention. The response rate for the two trials comparing racecadotril to placebo or octreotide in reducing bowel movements from baseline to that after treatment which was -0.13 ( $95 \%$ CI -0.26 to 0.01 , $\mathrm{Z}=1.84, \mathrm{p}<0.07)$ was not significant. Heterogeneity was statistically insignificant $\left(\mathrm{p}=1, \mathrm{I}^{2}=0 \%\right)$.

The study by Baumer et al. measured other outcomes such as the stool weight, lipid content, nitrogen content, and adverse events. Stool weight was not significantly reduced by both octreotide and racecadotril. ${ }^{5}$ Fecal lipid output decreased by $39 \%$ in the racecadotril group and increased by $78 \%$ in the octreotide group. However, this is not statistically significant. There was no change in fecal nitrogen output in both treatment arms. ${ }^{5}$ There was no significant difference in the frequency of adverse events between octreotide and racecodotril. Reported adverse events for the trial were nausea, anorexia, anal burning, spontaneous abdominal pain, pain on abdominal palpation, and abdominal distension.

\section{Limitations}

A thorough search of both online and offline databases was done to obtain studies included in this meta-analysis. However, only two articles fitted the predetermined criteria of the authors, both of which were published in the 1990s. This predates the current standards of randomized controlled trials such that some characteristics of good quality studies like allocation concealment, blinding and intention-to-treat analysis were not adequately followed, or if followed, were not explicitly stated.

The studies included in this meta-analysis were both randomized trials. Beaugerie, et al. focused on inpatient subjects and included a small number of participants, limiting the generalizability of the study's results. Baumer, et al. included a total of 174 participants. However, the article could not be thoroughly evaluated since the full article was not accessed. In addition, given that the bulk of participants included in the analysis come from the study of Baumer, et al., there was minimal heterogeneity observed in the results. Since the quality of Baumer's study could not be adequately assessed, results which favored the benefit of racecadotril in the symptomatic treatment of noninfectious, chronic diarrhea in patients diagnosed with HIV should be interpreted with caution.

Most of the available studies assessing the efficacy of racecadotril include participants with infectious diarrhea in both the adult and pediatric population. Diarrhea is a common symptom in HIV patients. It greatly affects their quality of life. Different pharmacologic agents, including enkephalinase inhibitors, and non-pharmacologic interventions may be tried for symptomatic relief. However, currently, there are no available guidelines in addressing chronic, non-infectious diarrhea in HIV patients.

\section{CONCLUSION}

There is some evidence pointing to a benefit in using enkephalinase inhibitors in the management of HIV and AIDS-associated, non-infectious diarrhea in terms of decreasing the frequency of loose bowel movement. Currently, there is a lack of well-designed multi-center randomized trials in evaluating the efficacy and safety of racecadotril, particularly in patients diagnosed with HIV and AIDS-associated, non-infectious diarrhea. An 
individualized approach is still recommended in the use of racecadotril for HIV patients with diarrhea.

\section{Statement of Authorship}

All authors have participated fully in the conceptualization, data collection, analysis, and have read and approved the final manuscript.

\section{Author Disclosure}

All authors declared no conflicts of interest.

\section{Funding Source}

This paper was funded by the authors.

\section{REFERENCES}

1. Elfstrand L, Florén CH. Management of chronic diarrhea in HIVinfected patients: current treatment options, challenges and future directions. HIV/AIDS (Auckland, NZ) 2010; 2:219-24.

2. Manatsathit S, Tansupasawasdikul S, Wanachiwanawin D, Setawarin S, Suwanagool P, Prakasvejakit S, et al. Causes of chronic diarrhea in patients with AIDS in Thailand: a prospective clinical and microbiological study. J Gastroenterol. 1996;31(4):533-7.

3. Clay PG, Crutchley RD. Noninfectious diarrhea in HIV seropositive individuals: a review of prevalence rates, etiology and management in the era of combination antiretroviral therapy. Infect Dis Ther. 2014; 3(2):103-22.

4. Beaugerie L, Baumer P, Chaussade S, Berard H, Rozenbaum W, Pialoux $\mathrm{G}$, et al. Treatment of refractory diarrhoea in AIDS with acetorphan and octreotide: a randomized crossover study. Eur J Gastroenterol Hepatol. 1996; 8(5):485-9.

5. Baumer P, Duvivier C, Bérard H, Pialoux G, Fretault N, Rozenbaum W, et al. HIV-related diarrhea: efficacy of acetorphan in a randomized controlled trial. Gastroenterology. 1995; 108(4):A778.

6. Vetel JM, Berad H, Fretault N, Lecomte JM. Comparison of racecadotril and loperamide in adults with acute diarrhea. Aliment Pharmacol Ther. 1999;13 Suppl 6:21-6.
7. Gallelli L, Colosimo M, Tolotta GA, Falcone D, Luberto L, Curto LS, et al. Prospective randomized double-blind trial of racecadotril compared with loperamide in elderly people with gastroenteritis living in nursing homes. Eur J Clin Pharmacol. 2010; 66(2):137-44.

8. Wang HH, Shieh MJ, Liao KF. A blind, randomized comparison of racecadotril and loperamide for stopping acute diarrhea in adults. 2005. World J Gastroenterol. 2005; 11(10):1540-3.

9. Prado D. A multinational comparison of racecadotril and loperamide in the treatment of acute watery diarrhoea in adults. Scand J Gastroenterol. 2002; 37(6):656-61.

10. Hamza H, Khalifa HB, Baumer P, Berard H, Lecomte JM. Racecadotril versus placebo in the treatment of acute diarrhea in adults. Aliment Pharmacol Ther. 1999;13 (Suppl. 6): 15-9.

11. Roge J, Baumer P, Berard H, Schwartz JC, Lecomte JM. The enkephalinase inhibitor, acetorphan, in acute diarrhoea. A doubleblind, controlled clinical trial versus loperamide. Scand J Gastroenterol. 1993; 28(4):352-4.

12. Lecomte JM. An overview of clinical studies with racecadotril in adults. Int J Antimicrob Agents. 2000; 14(1):81-7.

13. Hao R, De Vera M, Resurreccion E. Racecadotril in the treatment of acute diarrhea in children: a meta-analysis. Pediatric Infectious Disease Society of the Philippines Journal. 2010; 11(2):19-32.

14. Bergmann JF, Chaussade S, Couturier D, Baumer P, Schwartz JC, Lecomte JM. Effects of acetorphan, an anti-diarrheal enkephalinase inhibitor on oro-caecal and colonic transit times in healthy volunteers. Aliment Pharmacol Ther. 1992; 6(3):305-13.

15. Matheson AJ, Noble S. Racecadotril. Drugs. 2000; 59(4):829-35.

16. Baumer O, Dorval ED, Bertrand J, Vetel JM, Schwartz JC, Lecomte JM. Effects of acetrophan, an enkephalinase inhibitor, on experimental and acute diarrhea. Gut. 1992; 33(6):753-8.

17. Fischbach W, Andresen V, Eberlin M, Mueck T, Layer P. A comprehensive comparison of the efficacy and tolerability of racecadotril with other treatments of acute diarrhea in adults. Front Med. 2016; 3:44.

18. Cello JP, Grendell JH, Basuk P, Simon D, Weiss L, Wittner M, et al. Effect of octreatide on AIDS-associated diarrhea: A prospective, multicenter clinical trial. Ann Intern Med. 1991; 115(9):705-10.

19. Simon DM, Cello JP, Valenzuela J, Levy R, Dickerson G, Goodgame $\mathrm{R}$, et al. Multicenter trial of octreotide in patients with refractory acquired immunodeficiency syndrome-associated diarrhea. Gastroenterology. 1995; 108(6):1753-60. 